\title{
Treatment of Recurrent Urinary Tract Infection Symptoms with Urinary Antiseptics Containing Methenamine and Methylene Blue: Analysis of Etiology and Treatment Outcomes
}

This article was published in the following Dove Press journal:

Research and Reports in Urology

\section{Carlos Romualdo Barbosa \\ Gama ' \\ Manoel Antônio Gonçalves \\ Pombo iD ' \\ Carlos Pereira Nunes (iD) \\ Gustavo Falcão \\ Gama' \\ Spyros GE Mezitis ${ }^{2}$ \\ Mendel Suchmacher Neto ${ }^{3}$ \\ Oscar Roberto Guimarães (D) ${ }^{1}$ \\ Mauro Geller (D) 1,4 \\ Lisa Oliveira (iD) 4 \\ Adenilson de Souza da Fonseca' \\ Aline Sitnoveter' \\ Gerson Goldwasser ${ }^{3}$ \\ Karin Soares Cunha ${ }^{5}$ \\ Luiz Guilherme Darrigo \\ Junior (ID ${ }^{6}$ \\ 'UNIFESO Medical School, Rio de Janeiro, Brazil; ${ }^{2}$ New York-Presbyterian Hospital/ Weill-Cornell Medical Center, New York, NY, USA; ${ }^{3}$ Santa Casa de Misericórdia do Rio de Janeiro, Rio de Janeiro, Brazil; ${ }^{4}$ Universidade Federal do Rio de Janeiro (UFRJ), Rio de Janeiro, Brazil; ${ }^{5}$ Pathology Department, Faculdade de Medicina - Universidade Federal Fluminense (UFF), Niterói, Brazil; ${ }^{6}$ Ribeirão Preto Medical School, University of São Paulo, Ribeirão Preto, Brazil}

Correspondence: Mauro Geller Av. Ataulfo de Paiva, 135 sl. II04, Rio de Janeiro, RJ 22440-90I, Brazil

Tel $+55213875-6660$

$\mathrm{Fax}+55212259-3395$

Email maurogeller@gmail.com
Purpose: Urinary antiseptics including methenamine and methylene blue are used in the symptomatic treatment of urinary tract infections (UTIs).

Patients and Methods: This was a prospective, double-blind, randomized, double-dummy safety and efficacy study of 2 urinary antiseptic combinations in the symptomatic treatment of recurrent cystitis: methenamine $120 \mathrm{mg}+$ methylene blue $20 \mathrm{mg}$ (Group A) versus acriflavine $15 \mathrm{mg}+$ methenamine $250 \mathrm{mg}+$ methylene blue $20 \mathrm{mg}+$ Atropa belladonna L. $15 \mathrm{mg}$ (Group B). All subjects underwent pretreatment urine culture and antibiotic sensitivity tests prior to 3-day oral treatment with study drug, followed by 3 days of antibiotic therapy (based on urine culture) + study drug treatment. Efficacy was evaluated using the Urinary Tract Infection Symptoms Assessment Questionnaire (UTISA). The primary endpoint was the percentage of patients presenting improvement in cystitis manifestations on the UTISA domain "Urination Regularity" at Visit 2. The primary safety variable was the incidence of treatment-related adverse events.

Results: A total of 144 subjects were randomized per group and 272 completed the study. Primary endpoint analysis demonstrates homogeneity between treatment groups, with $69.4 \%$ and $72.2 \%$ subjects, respectively, showing improvement in the score of the urinary regularity UTISA domain after 3 days of treatment ( $p=0.87$ ). At Visit 2 , incidence of treatment-related adverse events was higher in Group B (Group A: $\mathrm{n}=11$, Group B: $\mathrm{n}=31, p=0.0057$ ).

Conclusion: Both treatments were effective in reducing UTI symptoms assessed by UTISA questionnaire after 3 days of treatment. The two regimens were comparable in incidence of adverse events, but the combination of methenamine + methylene blue resulted in fewer treatment-related adverse effects.

Keywords: urinary tract infection; UTI, urinary antiseptics, UTISA, methenamine, methylene blue

\section{Introduction}

Urinary tract infections (UTIs) are common bacterial infections occurring in both hospital and community settings, affecting individuals of both sexes and in all age ranges. ${ }^{1}$ Among individuals under 50 years of age, the incidence of UTIs in males is low, with women being up to 30 times more likely to develop a UTI. ${ }^{2}$ The increased risk among women is attributed to facilitated bacterial entry into the urinary tract on account of anatomical factors including a shorter urethra and urethral proximity increasing contact with vaginal and rectal pathogens, in addition 
to incomplete voiding of the urinary bladder and exposure to pathogens during intercourse. ${ }^{2,3}$ Approximately $90 \%$ of UTIs are caused by Escherichia coli bacteria, which can be found in the stool and can colonize the urethra, causing urethritis, the urinary bladder (cystitis), and eventually reaching the kidneys (pyelonephritis). ${ }^{1,3}$ Uropathogens other than E. coli, including Klebsiella pneumoniae, Enterobacter spp., P. aeruginosa, Proteus mirabilis, and Enterococcus spp., are most often identified in UTIs among patients under risk factors (RF) for complicated UTIs. $^{2}$

RFs for UTIs among women include sexual activity, diaphragm and spermicide use, genetic predisposition factors, change in sexual partner, previous UTIs, and postmenopausal state. ${ }^{2,4,5}$ Uncircumcised men present a higher risk of a UTI compared to circumcised men, and have a higher risk with advancing age due to prostatic hypertrophy. ${ }^{6}$ Other RFs include urinary catheterization, surgery involving the urinary tract, anatomical alteration or blockage of the urinary tract, inability to fully void the bladder, pregnancy, diabetes, and aged over 65 years. $^{7-9}$

The European Association of Urology's ORENUC classification system stratifies UTIs according to clinical presentation, RFs, and severity. ${ }^{9}$ In this system, adults presenting with uncomplicated UTIs are classified as O (no known/associated RF), R (Recurrent UTI RF, but no risk of severe outcome), and sometimes E (Extraurogenital RF, with risk of more severe outcome) classes, while complicated UTIs are categorized as $\mathrm{N}$ (Nephropathic disease, with risk of more severe outcome), U (Urological RF, with risk of more severe outcome, which can be resolved during therapy) and $\mathrm{C}$ (Permanent urinary catheter and non-resolvable urological RF, with risk of more severe outcome). ${ }^{1,9}$ The typical signs and symptoms of urethral and bladder infection include pollakiuria, alguria and burning on urination, suprapubic discomfort, vesical tenesmus, malaise, cloudy urine or presence of blood, and low fever. ${ }^{1}$ In cases of pyelonephritis, the symptoms include high fever, headache, chills and low back pain. ${ }^{1,3}$ The patient may also present a complete clinical picture of UTIs, with cystitis and pyelonephritis. ${ }^{4}$ Diagnosis is usually based on history and physical examination, and may be complemented with urinalysis and urine culture. ${ }^{9,10}$

UTI treatment objectives include alleviating symptoms and eliminating the causative agent, thus preventing infection dissemination and the formation of parenchymatous lesions. $^{7,11}$ The most commonly employed antibiotics include trimethoprim sulfamethoxazole, fluoroquinolones, and cephalosporins. ${ }^{4,7,12}$

Recurrence of UTIs is common, especially in female patients. ${ }^{5}$ Recurrent UTIs are associated with both personal (social and psychological impact negatively affecting quality of life) and societal (clinical and economic) disease burden. ${ }^{2,10}$ Consultations for UTIs account for $1-6 \%$ of all medical visits, with an annual cost of approximately US $\$ 1.6$ billion. ${ }^{11}$ Preventive measures for UTI recurrence include change of contraceptive method, increased fluid intake, urination after sexual activity, long-term antibiotic therapy, consumption of cranberry juice and fruit products, and urinary antiseptics. ${ }^{7,13}$

Methenamine is a urinary antiseptic commonly used in the prophylaxis and treatment of chronic and recurrent uncomplicated lower UTIs. ${ }^{13,14}$ Its bactericidal properties are due to the release of formaldehyde by hydrolysis in acid $\mathrm{pH}$ environments, to which most Gram-positive and Gram-negative bacteria are susceptible. ${ }^{13}$

Methylthioninium hydrochloride, also known as methylene blue, is a thiazine dye related to the monoamine oxidase inhibitor group that exhibits urinary antiseptic action upon oral administration following reduction to leukomethylene blue. ${ }^{15}$ Repeated and long-term use of both methenamine and methylthioninium hydrochloride as urinary antiseptics is considered attractive since there is no bacterial resistance development. ${ }^{16}$ In this study, we sought to investigate use of the combination of methenamine and methylene blue, available in commercially available oral formulations in Brazil (Sepurin $^{\circledR}$ and Cystex ${ }^{\circledR}$ ), in the symptomatic relief of cystitis prior to initiation of antibacterial treatment.

\section{Patients and Methods Study Design}

This was a double-blind, randomized, double-dummy, comparative study in parallel groups of patients with recurrent cystitis (defined as $\geq 2$ episodes within the last 6 months) performed at UNIFESO in the State of Rio de Janeiro, Brazil. The primary objective of this study was to evaluate the use of the combination of methenamine and methylene blue in the treatment of recurrent cystitis. The secondary objectives were to evaluate safety and efficacy of the combination of methenamine and methylene blue in the treatment of cystitis symptoms, and to compare the efficacy and safety of the combination of methenamine and methylene blue versus the combination of acriflavine 
+ methenamine + methylene blue + Atropa belladonna

L. in the treatment of cystitis symptoms.

Written informed consent was obtained from each patient. The protocol was conducted in accordance with the Declaration of Helsinki and Good Clinical Practice guidelines. The study protocol and related documents received approval from the institution's ethical committee (Comitê de Ética em Pesquisa do UNIFESO approval no. 2.434.612) and the study was registered at ClinicalTrials. gov under the number NCT03379389.

\section{Patient Population}

Inclusion criteria specified age $\geq 18$ years, recurrent cystitis, and required that female patients be neither pregnant nor breastfeeding and used birth control during the treatment period. Subjects presenting history of nephritis or renal calculi, diabetes, open-angle glaucoma or anatomical changes contributing to recurrent cystitis (as evidenced by imaging exams) were not included in the study. Subjects with urine culture identifying Proteus spp. and Pseudomonas spp. were withdrawn at Visit 2.

\section{Study Procedures}

After obtaining informed consent and screening for inclusion and non-inclusion criteria, subjects were randomized into one of two treatment groups in order of arrival to study center.

The randomization list was generated using a randomallocation software. Randomization was generated sequentially, at a ratio of 1:1 for two treatment groups, in blocks of 10. Table 1 summarizes the schedule of study procedures. At Visit 1, randomized subjects underwent pretreatment assessments (medical history, physical exam, vital signs, cystitis history), and urine was collected for culture and antibiotic sensitivity tests. Visit 2 occurred at the end of 3 days of treatment with the urinary antiseptics; patients returned to the study center for evaluations, and antibiotic therapy was initiated based on the urine culture/bacterial sensitivity result. Visit 3/Final Study Visit occurred after 3 additional days of treatment with antibiotic and study medication.

Efficacy was evaluated using the Urinary Tract Infection Symptoms Assessment Questionnaire (UTISA). ${ }^{17}$ Using this questionnaire, the patient assessed the degree of severity and bothersomeness on a scale of $0-3(0=$ absence of symptom; $3=$ most severe/bothersome) of the following 7 UTI symptoms: urgency of urination, frequency of urination, pain or burning when passing urine, urinary retention, pressure in the lower abdomen or pelvic area, lower back pain, and blood in the urine. The UTI symptoms scored with the UTISA are divided into four domains: urination regularity, problems with urination, pain associated with UTIs and hematuria. The questionnaire also includes an overall rating of UTI severity on a scale of 0 (no symptoms) to 3 (severe symptoms). Follow-up UTISA includes two questions regarding improvement from previous evaluation, $(0=$ about the same; $1=$ better; $2=$ worse), and how much improvement from previous evaluation, on a scale of 1-6 ( $1=$ a little better; $6=$ a very great deal better).

The investigating physician also evaluated patient global condition on a 10-point scale with 1 point representing the worst possible evaluation and 10 the best possible global condition. Overall efficacy and tolerability were evaluated by the investigating physician during the final study visit, who classified both as "Very Good," "Good," "Fair" or "Poor."

Safety evaluations throughout the treatment period included adverse event monitoring, in terms of: occurrence,

Table I Schedule of Study Procedures

\begin{tabular}{|c|c|c|c|c|c|c|c|}
\hline Study Visit & Visit I & & & Visit 2 & & & Visit 3 \\
\hline Study Day & Day 0 & Day I & Day 2 & Day 3 & Day 4 & Day 5 & Day 6 \\
\hline Inclusion/Exclusion Criteria & $\mathrm{x}$ & & & & & & \\
\hline Randomization & $x$ & & & & & & \\
\hline Physical Exam & $\mathrm{x}$ & & & $\mathrm{x}$ & & & $\mathrm{x}$ \\
\hline Laboratory Tests & $x$ & & & $x$ & & & \\
\hline Urine Culture + Bacterial Sensitivity & $x$ & & & & & & \\
\hline UTISA Questionnaire & $x$ & & & $x$ & & & $x$ \\
\hline Physician Assessment & $x$ & & & $x$ & & & $x$ \\
\hline Adverse Event Monitoring & $x$ & $x$ & $x$ & $x$ & $x$ & $x$ & $x$ \\
\hline Concomitant Medication Monitoring & $x$ & $x$ & $x$ & $x$ & $x$ & $x$ & $x$ \\
\hline Oral Urinary Antiseptic Treatment & $x$ & $x$ & $x$ & $x$ & $x$ & $x$ & \\
\hline Oral Antibiotic Treatment & & & & $\mathrm{x}$ & $\mathrm{x}$ & $\mathrm{x}$ & \\
\hline
\end{tabular}


severity (mild/moderate/severe), duration and causality (relation to study medication) as well as monitoring of laboratory tests performed at each study visit, including: $\mathrm{CBC}$, fasting blood glucose, AST, ALT, urea, uric acid, and creatinine.

\section{Study Drugs}

\section{Urinary Antiseptics}

Subjects were randomized into one of two treatment groups: Group A or Group B. Group A received a combination of $120 \mathrm{mg}$ methenamine and $20 \mathrm{mg}$ methylthioninium at the dose of 2 coated tablets, 3 times a day. Group B received a combination of $15 \mathrm{mg}$ acriflavine $+250 \mathrm{mg}$ methenamine + $20 \mathrm{mg}$ methylthioninium $+15 \mathrm{mg}$ Atropa belladonna $\mathrm{L}$., at the dose of 3 coated tablets, twice daily. Treatment duration with urinary antiseptics lasted a total of six consecutive days. The urinary antiseptics were administered in double-dummy fashion in order to maintain double-blind evaluation between the two treatments.

\section{Antibiotic Therapy}

At Visit 2, patients were prescribed open-label antibiotic therapy based on the results of the urine bacterial sensitivity testing performed at Visit 1 . Treatment duration was determined on an individual basis, depending on the antibiotic prescribed according to the urine bacterial sensitivity test result.

\section{Statistical Analysis}

The primary study endpoint was the percentage of patients presenting improvement in cystitis manifestations on the UTISA domain "Urination Regularity" at Visit 2. Secondary endpoints included Visit 2 evolution of the total UTISA score, evolution of the remaining UTISA domain scores, percentage of subjects with improvement in UTISA question 9 (changes in UTI severity), and the incidence of adverse events related to the study medication in each treatment group.

Sample size determination was based on the primary endpoint, estimating a difference between proportions with a two-tailed test, with an alpha of 0.05 and power of $90.2 \%$. The study $\mathrm{n}$ was determined with 109 patients per treatment group, considering a maximum acceptable difference between the treatment groups of 0.20. Based on these parameters it would be possible to report the difference between proportions with an accuracy of approximately 0.12 points $(95 \%$ confidence interval). Taking into account an estimated 30\% loss rate (dropouts, loss of follow-up and withdrawal of patients with positive cultures for Proteus spp. and Pseudomonas spp.), the total number of subjects required for this study was 284 evaluable patients.

Study data were analyzed using GraphPad Prism software, version 8.4.3 for Windows (GraphPad Software, San Diego, California USA, www.graphpad.com). Baseline and demographic data were compared between groups using unpaired $t$-test or Fisher's exact test for continuous and categorical variables, respectively. Primary and efficacy endpoint analysis was performed using the Fisher's exact test for the intent-to-treat (ITT) population. For analysis of continuous variables, data were analyzed for the ITT population using mixed effects analysis followed by Tukey's multiple comparisons test. For comparisons of categorical variables, we used the $\chi^{2}$ or Fisher's test, or mixed effects analysis for repeated measures.

\section{Results Subject Disposition}

A total of 503 subjects were screened between March and November 2018 and 288 subjects were randomized to treatment, with 144 subjects in each treatment group (Figure 1). Sixteen subjects were removed at the end of Visit 2 for the following reasons: Adverse event (Group A: $\mathrm{n}=1$; Group $\mathrm{B} \mathrm{n}=3$ ); Urine culture positive for Proteus spp., (Group A: $n=1$; Group B: $n=1$ ); Need for parenteral antibiotics (Group A: n= 3; Group B $n=3$ ); Withdrawn consent (Group A: $n=3$; Group B: $n=1$ ). A total of 272 subjects completed the study, 136 per treatment group.

\section{Baseline Characteristics}

The demographic and pretreatment data are summarized in Table 2. With the exception of mean participant age, where there was a statistically significant difference between the two treatment groups, pretreatment and demographic characteristics were comparable between groups. A majority of patients in both treatment groups reported previous cystitis treatment with antibiotics and half of all patients in both treatment groups reported previous treatment with urinary antiseptics.

Table 3 displays the UTISA total and domain scores at each study visit. Mean pretreatment UTISA total domain scores were comparable between treatment groups (19.0 and 17.8 in Group A and Group B, respectively; $p=0.11$ ). Pretreatment patient overall UTI severity assessment was comparable between groups (Group A: 15 patients with score of 1, 80 patients with score of 2 and 49 patients with 


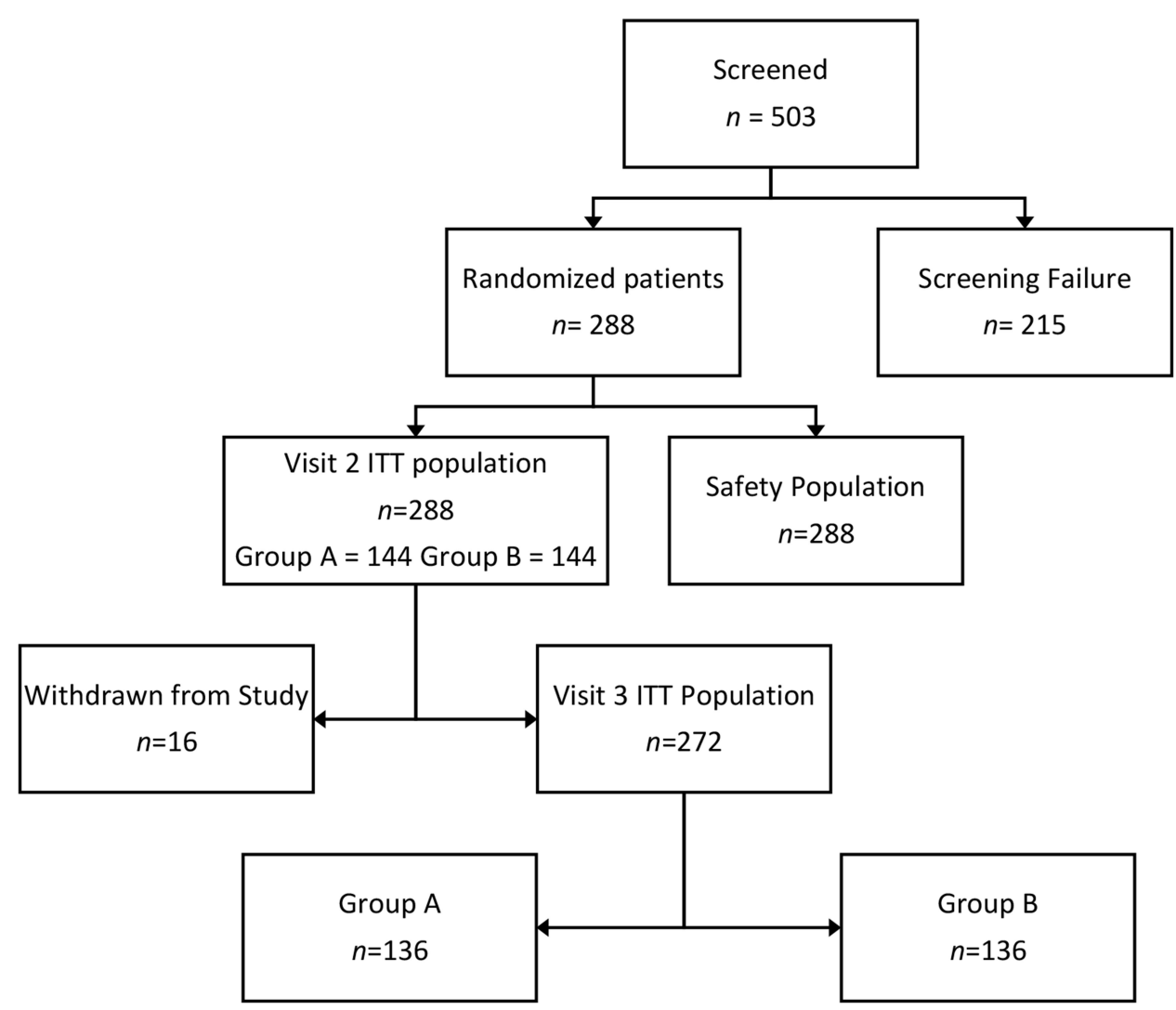

Figure I Flowchart of patients through the study.

score of 3; Group B: 26 patients with score of 1, 67 patients with score of 2 and 51 patients with score of 3; $\chi 2=4.141, d f=3 ; p=0.247$ ) Physician global evaluation scores at pretreatment were also comparable between treatment groups $(p=0.097)$.

\section{Results at Visit 2 (3 Days of Treatment) Study Drug Efficacy}

Analysis of the primary endpoint (UTISA domain "Urination Regularity" after 3 days of treatment) reveals homogeneity between treatment groups $\left(\chi^{2}=0.278 ; d f=2\right.$; $p=0.87$ ), with $69.4 \%$ and $72.2 \%$ of patients in Group A and Group B, respectively, showing significant score improvement after 3 days of treatment (mean reduction of -6.778 in Group A and -8.813 in Group B; $p<0.0001$ for both groups).

Table 3 displays the UTISA total and domain scores at each study visit. In both treatment groups there was a statistically significant improvement in total UTISA scores at Visit $2(p<0.0001)$ in relation to pretreatment scores.

Figure 2 displays the results of the UTISA domains "Urination Regularity," "Problems with Urination," "Pain
Associated with UTI," and "Hematuria" at Visit 2 in relation to Visit 1. Analysis of the secondary endpoint evaluating the scores of the remaining UTISA domains ("Problems with Urination," "Pain Associated with UTI," and "Hematuria"), showed there was no between-group difference in the percentage of patients in each group presenting improvement of scores in relation to pretreatment in the domains "Problems with Urination" (93.8\% and $95.8 \%$ of patients presenting improvement in Group A and Group B, respectively) and "Pain Related to UTI" (63.9\% and $68.1 \%$ of patients presenting improvement in Group A and Group B, respectively). There was no change in either treatment group in the "Hematuria" domain (no patients reported hematuria during the study).

In the "Overall UTI Severity" evaluation of the UTISA at Visit 2 (Figure 3), there was a statistically significant $(p<0.0001)$ improvement observed in both treatment groups in relation to pretreatment assessment, with no significant difference between treatment groups at Visit 2 $\left(\chi^{2}=3.245, d f=3 ; p=0.3554\right)$.

In the evaluation of percentage of subjects with improvement in UTISA question 9 (changes in UTI 
Table 2 Demographic and Pretreatment Characteristics

\begin{tabular}{|c|c|c|c|}
\hline & Group A & Group B & $\begin{array}{l}\text { Between- } \\
\text { Group } \\
\text { Difference }\end{array}$ \\
\hline $\begin{array}{l}\text { Gender }(n) \\
\text { Female } \\
\text { Male }\end{array}$ & $\begin{array}{l}144(100 \%) \\
0(0 \%)\end{array}$ & $\begin{array}{l}\text { I } 43 \text { (99.31\%) } \\
\text { I (0.35\%) }\end{array}$ & $p=0.317$ \\
\hline $\begin{array}{l}\text { Ethnicity (n) } \\
\text { Asian } \\
\text { Black } \\
\text { Caucasian } \\
\text { Mulatto }\end{array}$ & $\begin{array}{l}3(2.08 \%) \\
23(15.97 \%) \\
63(43.75 \%) \\
55(38.19 \%)\end{array}$ & $\begin{array}{l}2(1.39 \%) \\
21(14.58 \%) \\
79(54.86 \%) \\
42(29.17 \%)\end{array}$ & $p=0.28$ \\
\hline Age (years) & $47.19( \pm 9.34)$ & $44.21( \pm 11.46)$ & $p=0.016$ \\
\hline Weight (kg) & $62.85( \pm 7.21)$ & $62.01( \pm 6.97)$ & $p=0.315$ \\
\hline BMI $\left(\mathrm{kg} / \mathrm{cm}^{2}\right)$ & $24.47( \pm 2.71)$ & $24.15( \pm 2.45)$ & $p=0.305$ \\
\hline $\begin{array}{l}\text { Blood pressure }(\mathrm{mmHg}) \\
\text { Systolic } \\
\text { Diastolic }\end{array}$ & $\begin{array}{l}120.0( \pm 7.68) \\
76.38( \pm 9.61)\end{array}$ & $\begin{array}{l}120.4( \pm 8.94) \\
78.38( \pm 9.42)\end{array}$ & $\begin{array}{l}p=0.832 \\
p=0.076\end{array}$ \\
\hline Heart rate (bpm) & $69.69( \pm 6.18)$ & $70.49( \pm 6.72)$ & $p=0.295$ \\
\hline Respiratory rate (ipm) & $15.62( \pm 2.04)$ & $15.95( \pm 1.80)$ & $p=0.143$ \\
\hline Cystitis duration (days) & $6.35( \pm 2.56)$ & $6.33( \pm 2.75)$ & $p=0.947$ \\
\hline $\begin{array}{l}\text { Number of cystitis } \\
\text { episodes (last } 6 \text { months) } \\
2 \\
3 \\
4\end{array}$ & $\begin{array}{l}104(72.2 \%) \\
35(24.3 \%) \\
5(3.5 \%)\end{array}$ & $\begin{array}{l}114(79.2 \%) \\
26(18.1 \%) \\
4(2.8 \%)\end{array}$ & $p=0.387$ \\
\hline $\begin{array}{l}\text { Previous treatment with } \\
\text { antibiotics }(\mathrm{n}) \\
\text { Yes } \\
\text { No } \\
\text { Unsure }\end{array}$ & $\begin{array}{l}117(81.3 \%) \\
6(4.2 \%) \\
21(15.6 \%)\end{array}$ & $\begin{array}{l}128(89.9 \%) \\
2(1.4 \%) \\
14(10.7 \%)\end{array}$ & $p=0.143$ \\
\hline $\begin{array}{l}\text { Previous treatment with } \\
\text { urinary antiseptics (n) } \\
\text { Yes } \\
\text { No } \\
\text { Unsure }\end{array}$ & $\begin{array}{l}72(50.0 \%) \\
42(29.2 \%) \\
30(20.8 \%)\end{array}$ & $\begin{array}{l}72(50.0 \%) \\
45(31.3 \%) \\
27(18.8 \%)\end{array}$ & $p=0.878$ \\
\hline
\end{tabular}

Note: Data are expressed as $\mathrm{n}(\%)$ or mean and $( \pm \mathrm{SD})$.

Abbreviations: bpm, beats per minute; cm, centimeter; ipm, inspiration per minute; kg, kilogram; $\mathrm{mmHg}$, millimeters of mercury.

severity), $88.2 \%$ of patients in Group A and $94.4 \%$ of patients in Group B reported improvement in UTI symptoms, with no significant between-group difference ( $p=$ 0.1087). The degree of improvement of UTI symptoms did not vary between patient groups at Visit $2\left(\chi^{2}=3.170\right.$; $d f=5 ; p=0.6737)$.

In both Group A and Group B, Physician Global Assessment scores showed significant improvement $(p<0.0001)$ at Visit 2 in relation to pretreatment values, with no significant between-group difference $(\chi 2=10.61$; $d f=9 ; p=0.304)$.

\section{Urine Culture and Bacterial Sensitivity Results}

Most of the patients in both treatment groups showed E. coli growth in the urine culture. The results of the urine cultures and bacterial sensitivity test result/antibiotic prescribed are displayed in Table 4.

\section{Results at Visit 3 (End-of-Study) Efficacy Evaluations}

Total UTISA scores at Visit 3 showed significant $(p<0.0001)$ reduction as compared to pretreatment scores in both Group A and Group B (mean reduction of $-19,98$ in Group A and $-18,53$ in Group B), with 114/136 and 101/136 patients in Group A and Group B, respectively, reporting absence of all UTI symptoms on the UTISA questionnaire $\left(\chi^{2}=4.497 ; d f=3 ; p=0.213\right)$ and maximum score of improvement in relation to pretreatment, with no significant between-group difference $\left(\chi^{2}=7.446\right.$; $d f=4 ; p=$ 0.1141). Visit 3 UTISA scores for the domains of "Urination Regularity," "Problems with Urination," and "Pain Related to UTI" showed significant improvement in relation to pretreatment values $(p<0.005$ for all domains in both treatment groups), with no significant betweengroup differences observed, while the "Hematuria" domain did not vary from pretreatment (no patients reporting hematuria). Physician Global Assessment scores at Visit 3 were significantly improved in relation to pretreatment, with no difference between Group A and Group B $\left(\chi^{2}=\right.$ 15.46; $d f=9 ; p=0.0792$ ).

\section{Safety Evaluations}

The primary safety variable was the incidence of adverse events related to the study medication in each treatment group. At Visit 2, 21 patients in Group A reported a total of 28 adverse events, while 32 patients in Group B reported a total of 51 adverse events, with no difference between treatment groups in the percentage of patients presenting adverse events $(p=0.746)$ (Table 5). However, there was a greater incidence of adverse events considered to be related to the study treatment among patients in Group B (11 adverse events in Group A vs. 31 adverse events in Group B; $\chi^{2}=$ $10,32 ; d f=2 ; p=0.0057)$. No serious adverse events were recorded during the treatment period.

There was no significant change in the physical exam and vital signs at Visit 2 and Visit 3 as compared to pretreatment values in either patient group $(p>0.05$ for 
Table 3 UTISA Scores at Pretreatment (VI), Visit 2 (V2), and Visit 3 (V3), ITT Population

\begin{tabular}{|c|c|c|c|c|c|c|c|c|}
\hline Treatment Group & Visit & Mean & SD & $95 \% \mathrm{Cl}$ & Min & Max & Median & QI; Q3 \\
\hline \multicolumn{9}{|l|}{ Total UTISA Scores } \\
\hline \multirow[t]{3}{*}{ Group A } & VI & 19.0 & 6.2 & {$[18.0 ; 20.0]$} & 8 & 38 & 18 & $14.0 ; 23.0$ \\
\hline & V2 & 12.9 & 7.4 & [II.7; I4.I] & 0 & 42 & 13 & $8.0 ; 16.0$ \\
\hline & V3 & 0.76 & 2.2 & {$[0.39 ; 1.1]$} & 0 & 19 & 0 & $0.0 ; 0.0$ \\
\hline \multirow[t]{3}{*}{ Group B } & VI & 17.8 & 6.6 & {$[16.7 ; 18.9]$} & 8 & 38 & 18 & $12.0 ; 22.0$ \\
\hline & V2 & 9.7 & 6.5 & {$[8.6 ; 10.8]$} & 0 & 30 & 8 & $4.0 ; 14.0$ \\
\hline & V3 & 0.85 & 1.6 & {$[0.58 ; 1.1]$} & 0 & 6 & 0 & $0.0 ; 1.5$ \\
\hline \multicolumn{9}{|c|}{ UTISA Domain: Urination Regularity } \\
\hline \multirow[t]{3}{*}{ Group A } & VI & 7.7 & 2.6 & {$[7.2 ; 8.1]$} & 4 & 12 & 8 & $6.0 ; 10.0$ \\
\hline & V2 & 5.3 & 2.9 & {$[4.8 ; 5.8]$} & 0 & 12 & 6 & $0.0 ; 7.0$ \\
\hline & V3 & 0.3 & 0.9 & {$[0.1 ; 0.4]$} & 0 & 6 & 0 & $0.0 ; 0.0$ \\
\hline \multirow[t]{3}{*}{ Group B } & VI & 7.0 & 2.5 & {$[6.4 ; 7.3]$} & 2 & 12 & 6.5 & $4.0 ; 8.0$ \\
\hline & V2 & 4.2 & 3.0 & {$[3.7 ; 4.7]$} & 0 & 12 & 4.0 & $2.0 ; 6.0$ \\
\hline & V3 & 0.2 & 0.7 & {$[0.1 ; 0.4]$} & 0 & 4 & 0 & I.0; 0.0 \\
\hline \multicolumn{9}{|c|}{ UTISA Domain: Problems with Urination } \\
\hline \multirow[t]{3}{*}{ Group A } & VI & 6.7 & 2.6 & {$[6.3 ; 7.1]$} & 0 & 12 & 6 & $4.0 ; 8.0$ \\
\hline & V2 & 3.2 & 2.1 & {$[2.9 ; 3.7]$} & 0 & 9 & 3 & $2.0 ; 5.0$ \\
\hline & V3 & 0.3 & 0.9 & {$[0.1 ; 0.4]$} & 0 & 7 & 0 & $0.0 ; 0.0$ \\
\hline \multirow[t]{3}{*}{ Group B } & VI & 6.6 & 2.6 & {$[6.2 ; 7.1]$} & 2 & 12 & 6 & $4.0 ; 8.0$ \\
\hline & $\mathrm{V} 2$ & 2.8 & 2.0 & {$[2.4 ; 3.1]$} & 0 & 9 & 3 & $2.0 ; 4.0$ \\
\hline & V3 & 0.5 & 1.2 & {$[0.3 ; 0.7]$} & 0 & 5 & 0 & $0.0 ; 0.0$ \\
\hline \multicolumn{9}{|c|}{ UTISA Domain: Pain Associated with UTI } \\
\hline \multirow[t]{3}{*}{ Group A } & VI & 4.1 & 2.4 & {$[3.7 ; 4.5]$} & 0 & 12 & 4 & $2.0 ; 6.0$ \\
\hline & V2 & 2.6 & 2.0 & {$[2.2 ; 2.9]$} & 0 & 9 & 2 & $2.0 ; 4.0$ \\
\hline & V3 & 0.2 & 0.8 & {$[0.1 ; 0.3]$} & 0 & 6 & 0 & $0.0 ; 0.0$ \\
\hline \multirow[t]{3}{*}{ Group B } & VI & 3.8 & 2.6 & {$[3.3 ; 4.2]$} & 0 & 12 & 4 & $2.0 ; 6.0$ \\
\hline & $\mathrm{V} 2$ & 1.6 & 1.9 & {$[1.4 ; 2.0]$} & 0 & 10 & 2 & $0.0 ; 2.0$ \\
\hline & V3 & 0.1 & 0.5 & {$[0.0 ; 0.2]$} & 0 & 3 & 0 & $0.0 ; 0.0$ \\
\hline
\end{tabular}

weight, BMI, blood pressure, heart rate, and respiratory rate), and no between-group differences were observed at Visit 2 or Visit 3 regarding these parameters.

\section{Discussion}

To our knowledge, this is the first double-blind, randomized study using a validated outcome measure to assess the efficacy and safety of urinary antiseptics containing methenamine and methylene blue in the treatment of cystitis. Previous studies on the use of methenamine and methylene blue in cystitis have focused primarily on prevention of recurrence, with favorable results reported in otherwise healthy patients. Cronberg et al (1987) reported superior prophylactic efficacy of methenamine over placebo, at the dose of $1 \mathrm{~g}$ twice daily following a 1-year randomized, double-blind, long-term, crossover study with interchange between methenamine and placebo at 6 months. ${ }^{18}$ Methenamine was superior to placebo in prevention of recurrent UTIs in healthy pre- and postmenopausal women over 6 and 12 months of treatment periods. ${ }^{19-21}$ Use of methenamine hippurate was evaluated for UTI prevention in a 2002 Cochrane Review by Lee et al, and updated in 2004 and 2012. The authors conclude that methenamine appears to be effective for UTI prevention in patients without renal tract abnormalities, with a low rate of adverse effects. Following bacteriuria resolution with antibiotic therapy, prophylactic administration of methenamine could reduce the UTI re-incidence and consequently the need for additional antibiotic therapy. ${ }^{22}$ More recently, a literature review by Chwa et al (2019) concluded 


\section{Evolution of UTISA Domains at Visit 2}

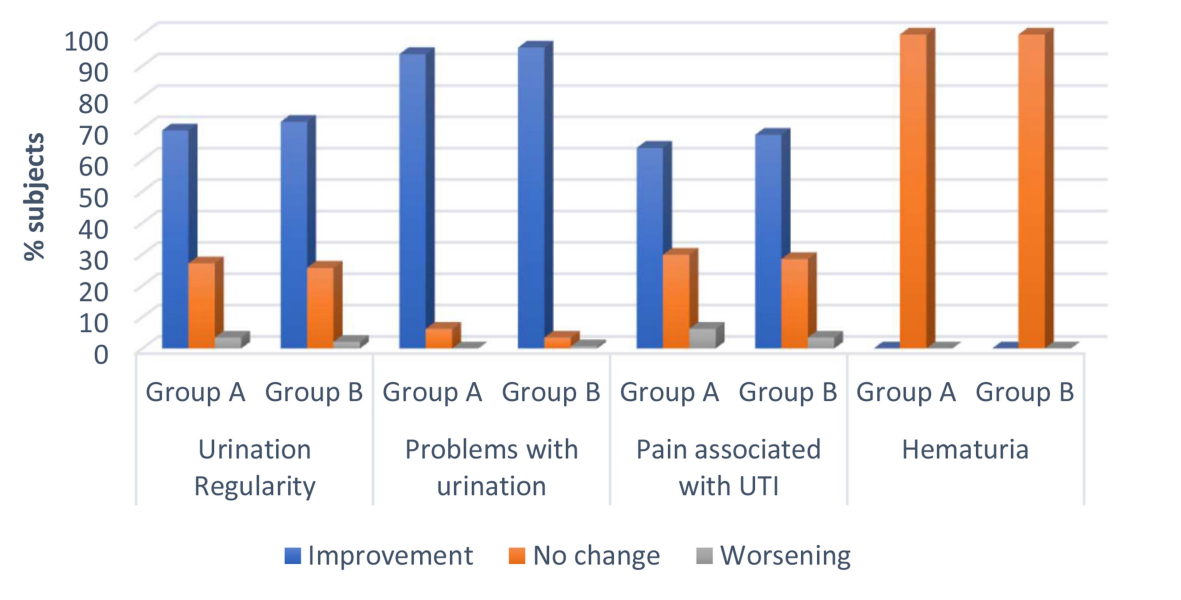

Figure 2 Evolution of UTISA domains (\%) after 3 days of treatment with study medication (Visit 2) in relation to pretreatment scores.

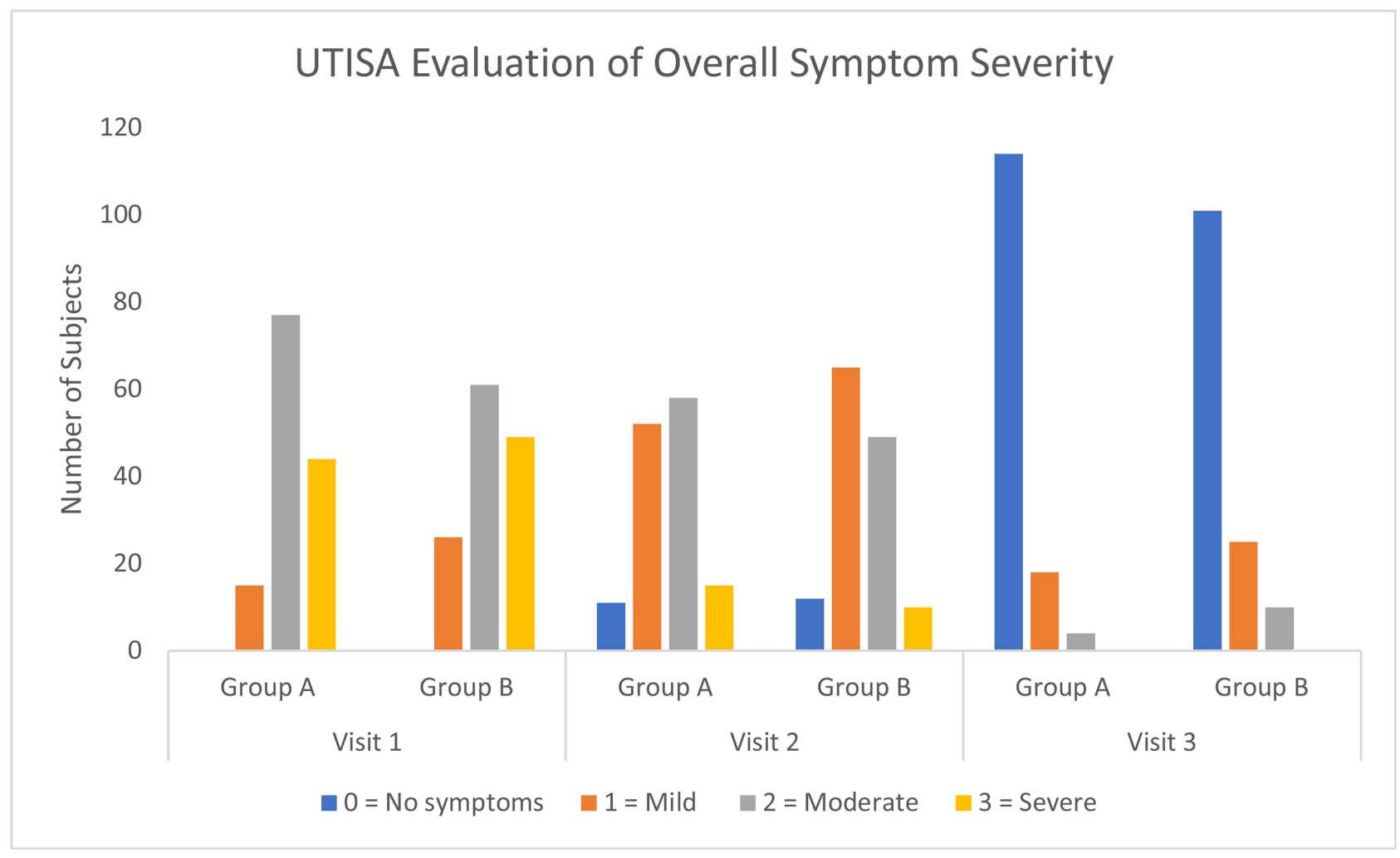

Figure 3 Evolution of UTISA overall symptom severity evaluation at pretreatment (Visit I), after 3 days of treatment with urinary antiseptics (Visit 2), and after 3 days of treatment with urinary antiseptics + antibiotic (Visit 3).

that methenamine may be safe and effective for preventing recurrent UTIs in adults aged 58 and older, including individuals submitted to genitourinary surgical procedures, and may potentially benefit patients in use of long-term catheterization. ${ }^{14}$
In 2008, Geller et al reported on the results of a retrospective study assessing the use of the combination of methenamine and methylene blue at the same concentrations used in the present study as prophylactics for recurrent uncomplicated lower UTIs. Treatment periods 
Table 4 Urine Culture and Bacterial Sensitivity Results

\begin{tabular}{|l|l|l|l|}
\hline Bacterial Growth & $\begin{array}{l}\text { Antibiotic } \\
\text { Sensitivity }\end{array}$ & $\begin{array}{l}\text { Group } \\
\text { A (n) }\end{array}$ & $\begin{array}{l}\text { Group } \\
\text { B (n) }\end{array}$ \\
\hline E. coli & Ceftazidime & $\mathrm{I}$ & 0 \\
E. coli & Cefuroxime & 0 & $\mathrm{I}$ \\
E. coli & Ciprofloxacin & 133 & 128 \\
E. coli & Nitrofurantoin & $\mathrm{I}$ & 0 \\
E. faecalis & Cefuroxime & 0 & $\mathrm{I}$ \\
Klebsiella & Ciprofloxacin & 2 & 2 \\
Klebsiella & Gentamicin & $\mathrm{I}$ & 0 \\
Morganella & Amikacin & 0 & $\mathrm{I}$ \\
Proteus & Ampicillin & $\mathrm{I}$ & 0 \\
Proteus & Ciprofloxacin & 0 & $\mathrm{I}$ \\
Providência stuartii & Trimethoprim/ & $\mathrm{I}$ & 0 \\
& sulfamethoxazole & & \\
Pseudomonas aeruginosa & Amikacin & $\mathrm{I}$ & 0 \\
S. aureus & Trimethoprim/ & 0 & $\mathrm{I}$ \\
S. saprophyticus & sulfamethoxazole & & \\
Serratia marcescens & Ciprofloxacin & 2 & 9 \\
\hline
\end{tabular}

Table 5 Adverse Events by MedDRA System-Organ-Class (SOC) at Visit 2

\begin{tabular}{|l|l|l|}
\hline SOC & $\begin{array}{l}\text { Group } \\
\text { A (n) }\end{array}$ & $\begin{array}{l}\text { Group } \\
\text { B (n) }\end{array}$ \\
\hline Cardiac disorders & $\mathrm{I}$ & $\mathrm{I}$ \\
Gastrointestinal disorders & 18 & 37 \\
General disorders and administration site & $\mathrm{I}$ & 0 \\
conditions & & \\
Infections and infestations & $\mathrm{I}$ & 0 \\
Investigations & $\mathrm{I}$ & 0 \\
Metabolism and nutrition disorders & $\mathrm{I}$ & 3 \\
Nervous system disorders & 3 & 5 \\
Psychiatric disorders & 0 & 2 \\
Respiratory, thoracic and mediastinal & $\mathrm{I}$ & 0 \\
disorders & & \\
Skin and subcutaneous tissue disorders & 0 & 3 \\
\hline
\end{tabular}

varied between 3-6 months, with daily oral doses of methenamine ranging from $360-720 \mathrm{mg}$ and $60-120 \mathrm{mg}$ of methylthioninium chloride. The authors reported significant reductions of UTI recurrence associated with treatment using the combination of methenamine and methylene blue. ${ }^{23}$

Methenamine has also been reported to aid in prevention of UTI recurrence among patients with related to comorbidities or following surgical procedures. Among patients who underwent utero-vaginal prolapse surgery, bacteriuria incidence was significantly reduced with prophylactic methenamine treatment. ${ }^{24}$ Methenamine together with acidification was reported to be superior to placebo in preventing UTIs among patients with neurogenic bladder who underwent intermittent catheterization. ${ }^{25}$ Methenamine also reduced the incidence of UTIs among patients with spinal cord injury-derived neurogenic bladder. ${ }^{26}$ When used prophylactically for prevention of post-operative bacteriuria after gynecological surgery, methenamine was reported to significantly reduce postoperative bacteriuria and UTIs. ${ }^{27}$

Hydrolyzation of methenamine leads to formation of ammonia and formaldehyde, which inhibits bacterial proliferation and lacks bacterial resistance. Hamilton-Miller and Brumfitt (1977) reported a minimal inhibitory concentration of formaldehyde of $13 \mu \mathrm{g} / \mathrm{mL}$. When in contact with urinary $\mathrm{pH}$ of 5-6, methenamine may produce an antibacterial concentration of formaldehyde within 1 hour. $^{28}$ Urine containing $0.6-1 \mathrm{mg} / \mathrm{mL}$ methenamine at $\mathrm{pH}$ ranging from 5.7-5.85 reaches concentrations of formaldehyde $\geq 25 \mu \mathrm{g} / \mathrm{mL}$, and a measurable bacteriostatic effect is observed after 2 hours. ${ }^{29}$ Oral administration of $1 \mathrm{~g}$ methenamine four times per day in healthy individuals was associated with inhibition of urinary pathogen growth, with urinary formaldehyde levels of $100-820 \mathrm{mcg}$, free formaldehyde of $3.2-16.6 \%$, and urinary $\mathrm{pH}$ of $5.7-6.2 .^{30}$

The adverse events recorded during the treatment period were transitory and there were no serious adverse events during the study. Previously reported adverse events during treatment with the combination of methenamine and methylene blue included headache, diarrhea, dyspepsia, epigastralgia, nausea, and cutaneous rash. ${ }^{23,31}$ The combination of acriflavine + methenamine + methylene blue + Atropa belladonna L. may be associated with decreased urine flow, gastrointestinal side effects including nausea, vomiting, and diarrhea, as well as dry mouth, dysphagia and speech difficulties, decreased bronchial secretion, pupil dilation, and skin redness and dryness. There is also a risk for skin hypersensitivity reactions, skin rash, eosinophilia, and anaphylaxis. ${ }^{32}$

The efficacy of the two study treatment regimens was equivalent in analysis of the primary and secondary endpoints. In the population evaluated in this study, the higher dose of methenamine and co-administration of acriflavine and Atropa belladonna L. did not produce statistically superior responses in patient or physician assessments among the treated subjects. Both treatments demonstrated efficacy in reducing the symptoms associated with UTIs. 
In light of the increasing concern over antibiotic resistance, the results of this study support the suggestion that the combination of methenamine and methylene blue may be effective for symptomatic UTI relief while awaiting urine culture and antibiotic sensitivity results, enabling start of antibiotic treatment only after confirmed identification of bacterial species and most effective antibiotic on an individual patient basis.

\section{Conclusion}

Both urinary antiseptic combinations were effective in improving UTI symptoms, with comparable percentages of subjects presenting improvements in cystitis manifestations on the UTISA domain "Urination Regularity" after 3 days of treatment (Visit 2). After 3 days of treatment, significant improvements in both treatment groups were observed for total UTISA score and UTISA domain scores "Problems with Urination" and "Pain Associated with UTI," and a comparable percentage of subjects had improvement in UTISA question 9 (changes in UTI severity). The two treatments were also comparable in terms of adverse event incidence, while patients treated with the combination of methenamine and methylene blue presented fewer urinary antiseptic treatment-related adverse effects, in the population evaluated in this study.

\section{Data Sharing Statement}

The authors agree to share study data upon request by e-mail to the corresponding author, via e-mail (maurogeller@gmail.com), to investigators whose proposed use of the data has been approved by an independent review committee or ethical committee and who agree to sign a data access agreement. Data to be shared includes individual deidentified participant data and study-related documents (i.e., study protocol, informed consent text, or other study documentation requested), for a period of five years from the date of study publication.

\section{Acknowledgments}

The authors thank Silvia Maciel, Natalia Platenik, and Thainá Zanon Cruz for study monitoring.

\section{Disclosure}

This study was sponsored by Laboratório Gross S.A. (Rio de Janeiro, RJ, Brazil). The authors report no other conflicts of interest in this work.

\section{References}

1. Kolman KB. Cystitis and pyelonephritis: diagnosis, treatment, and prevention. Prim Care. 2019;46(2):191-202. doi:10.1016/j. pop.2019.01.001

2. Foxman B. Urinary tract infection syndromes: occurrence, recurrence, bacteriology, risk factors, and disease burden. Infect Dis Clin North Am. 2014;28(1):1-13. doi:10.1016/j.idc.2013.09.003

3. Geerlings SE. Clinical presentations and epidemiology of urinary tract infections. Microbiol Spectr. 2016;4(5). doi:10.1128/microbiolspec.UTI-0002-2012

4. Li R, Leslie SW. Cystitis. In: StatPearls. Treasure Island (FL): StatPearls Publishing; 2020 June 7.

5. Guglietta A. Recurrent urinary tract infections in women: risk factors, etiology, pathogenesis and prophylaxis. Future Microbiol. 2017;12:239-246.

6. Spach DH, Stapleton AE, Stamm WE. Lack of circumcision increases the risk of urinary tract infection in young men. JAMA. 1992;267(5):679-681. doi:10.1001/jama.1992.03480050083029

7. Gupta K, Grigoryan L, Trautner B. Urinary tract infection. Ann Intern Med. 2017;167(7):ITC49-ITC64. doi:10.7326/AITC201710030

8. Hooton TM, Scholes D, Hughes JP, et al. A prospective study of risk factors for symptomatic urinary tract infection in young women. $N$ Engl $J \quad$ Med. 1996;335(7):468-474. doi:10.1056/ NEJM199608153350703

9. Tan CW, Chlebicki MP. Urinary tract infections in adults. Singapore Med J. 2016;57(9):485-490. doi:10.11622/smedj.2016153

10. Wagenlehner F, Wullt B, Ballarini S, et al. Social and economic burden of recurrent urinary tract infections and quality of life: a patient web-based study (GESPRIT). Outcomes Res. 2018;18(1):107-117.

11. Medina M, Castillo-Pino E. An introduction to the epidemiology and burden of urinary tract infections. Ther Adv Urol. 2019;11:1756287219832172. doi:10.1177/1756287219832172

12. Walker E, Lyman A, Gupta K, Mahoney MV, Snyder GM, Hirsch EB. Clinical management of an increasing threat: outpatient urinary tract infections due to multidrug-resistant uropathogens. Clin Infect Dis. 2016;63(7):960-965. doi:10.1093/cid/ciw396

13. Lo TS, Hammer KD, Zegarra M, Cho WC. Methenamine: a forgotten drug for preventing recurrent urinary tract infection in a multidrug resistance era. Expert Rev Anti Infect Ther. 2014;12(5):549-554. doi:10.1586/14787210.2014.904202

14. Chwa A, Kavanagh K, Linnebur SA, Fixen DR. Evaluation of methenamine for urinary tract infection prevention in older adults: a review of the evidence. Ther Adv Drug Saf. 2019;10:2042098619876749. doi:10.1177/2042098619876749

15. Schirmer RH, Adler H, Pickhardt M, Mandelkow E. Lest we forget you-methylene blue .... Neurobiol Aging. 2011;32(12):2325.e72325.e2.325E16. doi:10.1016/j.neurobiolaging.2010.12.012

16. Hooton TM, Besser R, Foxman B, Fritsche TR, Nicolle LE. Acute uncomplicated cystitis in an era of increasing antibiotic resistance: a proposed approach to empirical therapy. Clin Infect Dis. 2004;39 (1):75-80. doi:10.1086/422145

17. Clayson D, Wild D, Doll H, Keating K, Gondek K. Validation of a patient-administered questionnaire to measure the severity and bothersomeness of lower urinary tract symptoms in uncomplicated urinary tract infection (UTI): the UTI symptom assessment questionnaire. $B J U$ Int. 2005;96(3):350-359. doi:10.1111/j.1464-410X.2005.05630.x

18. Cronberg S, Welin CO, Henriksson L, Hellsten S, Persson KM, Stenberg P. Prevention of recurrent acute cystitis by methenamine hippurate: double blind controlled crossover long term study. Br Med J (Clin Res Ed). 1987;294(6586):1507-1508. doi:10.1136/bmj.294.6586.1507

19. Gundersen R, Høivik HO, Osmundsen K. Hyppig forekommende cystitter hos eldre kvinner. En dobbeltblind sammenligning av Hiprex og placebo i almenpraksis [Frequent cystitis in elderly women. A double-blind comparison of Hiprex and placebo in general practice]. Tidsskr nor Laegeforen. 1986;106(25):2048-2049. 
20. Høivik HO, Gundersen R, Osmundsen K, Halvorsen P, Hjortdahl P, Stokke JG. Profylakse ved residiverende cystitt hos fertile kvinner En dobbeltblind sammenligning av Hiprex og placebo i almenpraksis [Prevention of recurrent cystitis in fertile women. A double-blind comparison of Hiprex and placebo in general practice]. Tidsskr nor Laegeforen. 1984;104(16):1150-1152.

21. Keswani RK, Chugh TD, Hooda RS, Beniwal JS. Prevention of recurrent urinary tract infection with methenamine mandelate Indian J Med Res. 1976;64(8):1168-1172.

22. Lee BS, Bhuta T, Simpson JM, Craig JC. Methenamine hippurate for preventing urinary tract infections. Cochrane Database Syst Rev. 2012;10(10):CD003265.

23. Geller M, Gama CRB, Guimarães OR, et al. Recurrent urinary tract infections: evaluation of the prophylactic efficacy of urinary antiseptics methenamine and methylthioninium chloride. Rev Bras Med. 2008;65(11):367-371.

24. Tyreman NO, Andersson PO, Kroon L, Orstam S. Urinary tract infection after vaginal surgery. Effect of prophylactic treatment with methenamine hippurate. Acta Obstet Gynecol Scand. 1986;65 (7):731-733. doi:10.3109/00016348609161491

25. Kevorkian CG, Merritt JL, Ilstrup DM. Methenamine mandelate with acidification: an effective urinary antiseptic in patients with neurogenic bladder. Mayo Clin Proc. 1984;59(8):523-529. doi:10.1016/ S0025-6196(12)61489-X
26. Banovac K, Wade N, Gonzalez F, Walsh B, Rhamy RK. Decreased incidence of urinary tract infections in patients with spinal cord injury: effect of methenamine. J Am Paraplegia Soc. 1991;14 (2):52-54. doi:10.1080/01952307.1991.11735835

27. Schiøtz HA, Guttu K. Value of urinary prophylaxis with methenamine in gynecologic surgery. Acta Obstet Gynecol Scand. 2002;81 (8):743-746

28. Hamilton-Miller JM, Brumfitt W. Methenamine and its salts as urinary tract antiseptics: variables affecting the antibacterial activity of formaldehyde, mandelic acid, and hippuric acid in vitro. Invest Urol. 1977;14(4):287-291.

29. Musher DM, Griffith DP. Generation of formaldehyde from methenamine: effect of $\mathrm{pH}$ and concentration, and antibacterial effect. Antimicro Agents Chemother. 1974;6(6):708-711. doi:10.1128/ AAC.6.6.708

30. Gandelman AL. Methenamine mandelate: antimicrobial activity in urine and correlation with formaldehyde levels. J Urol. 1967;97 (3):533-536. doi:10.1016/S0022-5347(17)63074-X

31. Sepurin (methenamine + methylthioninium chloride coated tablets) [package insert]. Rio de Janeiro, RJ Brazil: Laboratório Gross S/A; 2013.

32. Cystex (acriflavin hydrochloride + methenamine + methylthioninium chloride + Atropa belladonna L coated tablets) [package insert]. São Bernardo do Campo, SP Brazil: EMS S/A; 2014.
Research and Reports in Urology

\section{Publish your work in this journal}

Research and Reports in Urology is an international, peer-reviewed, open access journal publishing original research, reports, editorials, reviews and commentaries on all aspects of adult and pediatric urology in the clinic and laboratory including the following topics Pathology, pathophysiology of urological disease; Investigation and
Dovepress

treatment of urological disease; Pharmacology of drugs used for the treatment of urological disease. The manuscript management system is completely online and includes a very quick and fair peer-review system, which is all easy to use. Visit http://www.dovepress.com/ testimonials.php to read real quotes from published authors. 